\title{
An Extensive Review on the Viscoelastic-plastic and Fractural Mechanical Behaviour of ETFE Membranes
}

\author{
Dániel Tamás Karádi ${ }^{*}$ Dezső Hegyi \\ ${ }^{1}$ Department of Mechanics, Materials and Structures, Faculty of Architecture, Budapest University of Technology and Economics, \\ H-1111 Budapest, Múegyetem rkp. 3., Hungary \\ ${ }^{*}$ Corresponding author, e-mail: karadi.daniel@epk.bme.hu
}

Received: 21 April 2021, Accepted: 15 November 2021, Published online: 20 December 2021

\begin{abstract}
The present article is a review of ETFE (ethylene tetrafluoroethylene) material, with emphasis on the mechanical and fractural behaviour, considering that the material is becoming one of the most promising façades and roof materials due to its advantageous properties. This paper examines the basic chemical makeup of this copolymer and details the elastic-plastic and viscous properties through selected studies in the field. The paper also reviews the available phenomenological, continuum mechanical or rheological constitutive models focusing on the engineering application to the corresponding phenomena. A separate part of the article covers the existing fractural mechanical research on ETFE.
\end{abstract}

Keywords

ethylene tetrafluoroethylene (ETFE), viscoelastic-plastic properties, mechanical behaviour, fracture mechanics

\section{Introduction}

Since the middle of the $20^{\text {th }}$ century, plastics have become one of the world's most popular and accessible materials. They are used in the building industry because of their cost-effective, lightweight properties as a replacement for conventional building materials such as wood and steel. Ethylene tetrafluoroethylene (ETFE) is a promising plastic with excwlent mechanical, chemical, light-transmissive, and relatively good thermal properties. For this reason, it is becoming an effective cladding material to substitute glass envelopes on environmental and aesthetic buildings from the 1980s (Moritz and Barthel, 2002).

ETFE was synthesized first in the 1940 s by DuPont. They aimed to develop friction and abrasion restraint, radiation immune, and extreme temperature bearing melt-processable thermo-plastic for machine insulation and cable coatings. ETFE is still used in aeronautical, automotive, nuclear and chemical industries as one of the most stable chemical compounds today (LeCuyer, 2008). After the first synthesize, it only needed just a few years to appear in architecture. Due to the oil crisis, at the end of the 1970s, it was tested in Arizona and Germany by replacing the glass in greenhouses. The experiments showed unexpectedly good results, and in 1981 numerous building roofs were designed with ETFE in Burges Zoo by Vector Foiltec as a replacement for the weaker FEP (Fluorinated ethylene propylene) membrane cladding. Since then, its popularity as a building façade material has risen (LeCuyer, 2008).

ETFE films are either used as single-layered tensile membrane structures or with multiple layers in inflated cushions. The latter is the most popular solution, providing better thermal insulation with the enclosed air. It also offers the possibility of sun shading by patterned extra film layers. One of the most famous examples is the Eden Project (2001) in the U.K., where ETFE was used in the geodesic domes as hexagonal and pentagonal inflated cells. It is also designed as an inflated cushion façade and roof element in Allianz Arena (2005) in Germany, the National Aquatics Center (2008) China and on the Biodóm in Budapest (under construction) shown in Fig. 1. Due to its lightweight properties, from the 2010s, it has been used in adaptive building design such as the aperture-like roof of the Mercedes Benz Stadium (2017) and the kinetic retractable façade of The Shed arts centre (2019).

ETFE is a high-tech material of the building industry. The extensive scientific investigations of ETFE membranes started at the beginning of the $21^{\text {st }}$ century, so the understanding of the material, especially its failure modes and fracture phenomena, is limited. The present paper reviews the state of the art of the mechanical properties of ETFE. 


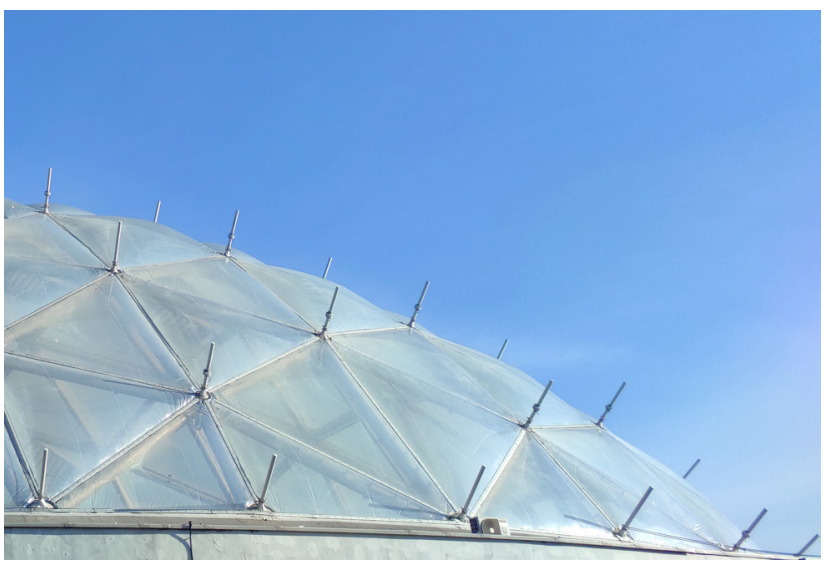

Fig. 1 ETFE covering on Biodóm by Pauliny-Reith \& Partners in Budapest (under construction, 2021)

The focus is on the mechanical parameters and the existing material models developed by other researchers in the field, which can help understand the fractural behaviour of ETFE membranes. Databases of SCOPUS and Web of Sciences were investigated for articles related to the mechanical or constitutive model of ETFE foils in the title or the keywords of the articles. Based on the abstracts of the collected articles, it was possible to conclude that the characteristics of a stress-strain diagram, the direction-dependent behaviour and the time-dependent behaviour are currently the most researched areas. The sections of this review article are structured based on these widely researched areas. In each section, the articles are introduced according to publication date with the described material model. The basic chemical properties and manufacturing types are described in Section 2. The uniaxial, biaxial and inflated bubble test experiments are introduced in Section 3. The elastoplastic material properties of ETFE, such as the elastic modulus and yield stress determination and material anisotropy, are introduced in Section 4. The time-dependent properties such as viscosity, creep and cyclic behaviour and the proposed constitutive models describing them are presented in Section 5. Literature on the fractural mechanical behaviour of the material is presented in Section 6. Conclusions are summarised in Section 7.

\section{The chemical structure and manufacturing of ETFE}

The ETFE is a partially fluorinated thermoplastic semicrystalline copolymer whose main ingredient is the mineral fluorite. The polymer chains bases are the ethylene and tetrafluoroethylene monomers (Ebnesajjad, 2013; Kerbow, 1997), forming alternated zigzag-like sequences in the resin (Fig. 2).

This structure is highly dependent on the polymerisation and manufacturing process when the highly organised tightly packed molecular chains form crystallinity areas,

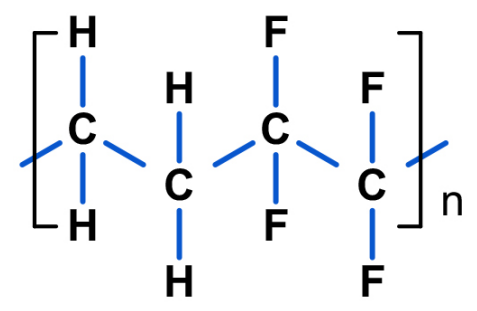

Fig. 2 Shows the molecular formula of ETFE.

spherulites, with amorphous areas between them. The degree of the spherulites and rate of alternates determine mainly the direction-dependent behaviour, viscoplastic and crack properties. This is because the molecular bonds in the chains are stronger than the weak van Der Waals bond between the chains (Charbonneau et al., 2014). The average rate of alternating sequences in ETFE is 88\% (Kerbow, 1997), and the average degree of spherulites is $30-45 \%$ (De Focatiis and Gubler, 2013). To improve the copolymers poor stress crack resistance, commercial ETFE polymers consist of modifiers of termonomers (1-10 mol\%). These are chosen to have little or no chain transfer activity in the polymerization and to have bulky pendant side chains to break up crystallinity in the resulting polymer (Kerbow, 1997). After synthesis of the resin, the manufacturing process can be one of the various types of melt fabrication techniques such as injection moulding, compression moulding, blow moulding, extrusion, and wire coating. In the building industry, extrusion and blow moulding are the main processes for thin-film sheets. During the extrusion manufacturing types, the film forms two major directions perpendicular to each other: the machine direction (M.D.), parallel with the extrusion, and the transverse direction (T.D.), orthogonal to M.D. It is possible to improve mechanical properties by adding glass fibre to the film as a composite material (Kerbow, 1997).

The type and manufacturing firm also determine the material properties. However, in general, the following advantages are almost valid for every ETFE material type. It has high transparency and light transmission, high U.V. resistance, wide temperature application range and good behaviour during a fire with low smoke and flame emission. The films have a long lifetime and low maintenance needs, weldability, many colour possibilities and no discolouring. They also have excellent electric insulation properties. Finally, it has good mechanical properties, such as high tensile strength and stiffness, which will be discussed in detail in the Sections 4-5. In Table 1-2, the typical characteristics and mechanical properties are described numerically. 
Table 1 Main physical properties of ETFE foils

\begin{tabular}{lc}
\hline Properties & Value \\
\hline Thickness $(\mu \mathrm{m})$ & $50-300$ \\
Density $\left(\mathrm{g} / \mathrm{cm}^{3)}\right.$ & $1.7-1.77$ \\
Light transmission $(\%)$ & Visible light: 95 ; UV-A: 85 \\
Temp. range of application $\left({ }^{\circ} \mathrm{C}\right)$ & $-200-+150$ \\
Glass transition temperature $\left({ }^{\circ} \mathrm{C}\right)$ & $70-85$ \\
Melting temperature $\left({ }^{\circ} \mathrm{C}\right)$ & $250-280$ \\
Processing temperature $\left({ }^{\circ} \mathrm{C}\right)$ & $300-345$ \\
Dielectric constant at $1 \mathrm{kHz}$ & 2.6 \\
Life cycle $(\mathrm{y})$ & $>25$ \\
\hline
\end{tabular}

Table 2 Main mechanical properties of ETFE foils

\begin{tabular}{lc}
\hline Properties & Value \\
\hline Tensile strength (MPa) & $38-64$ \\
Break strain (\%) & $250-650$ \\
Elastic modulus (MPa) & $300-1100$ \\
Poisson's ration (-) & $0.43-0.45$ \\
\hline
\end{tabular}

\section{Mechanical testing procedures}

To understand the results for the mechanical properties provided by the research, Section 3 summarizes the regular testing types with their advantages and disadvantages. As the ETFE is used as a thin film layer in the building industry for membrane structures or inflated cushions, only the tensile test types are introduced. Three major test type exists, namely the uniaxial, biaxial, and bubble inflation tests.

\subsection{The uniaxial test type}

The uniaxial tensile test is the most common method to determine the mechanical properties of ETFE foils. During the test, a rectangular or a dogbone-shaped specimen is clamped vertically into a uniaxial tensile test machine (Fig. 3). The rectangular-shaped specimen has

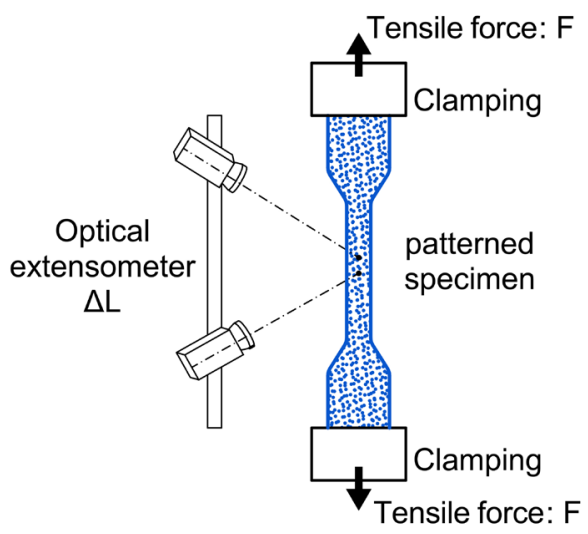

Fig. 3 Schematic drawing of the uniaxial tensile test on dogbone specimens with an optical extensometer system one major disadvantage: it tends to fail close to the clamped areas due to the stress concentration. However, in the dogbone specimens, the failure occurs in the controlled central zone of the specimen. Measuring the elongation is possible with mechanical or optical extensometers. The optical one is more advantageous because it provides more data, such as the Poisson ratio and the elongation in different directions; it also eliminates the effect of wrinkles. Another advantage of this test type is that the stress-strain curve is directly available. Furthermore, it is also possible to take into consideration the influences of the loading speed, loading time, temperature, and specimen direction.

\subsection{The biaxial test type}

During the biaxial tensile test, a cross-shape or a rectangular-shaped specimen is tested. It is possible to load the specimen independently through the grips on the edges, but it needs a more sophisticated test machine. It is important to note that the arms should be cut parallel with the loading direction to have homogeneous tensile stress in the middle of the specimen (Fig. 4). The stresses in the centre have to be deduced by a stress concentration factor from the stresses applied on the edges because of the non-uniform stress concentration (Galliot and Luchsinger, 2011). The strains can be measured with a mechanical or digital extensometer. The biaxial tensile test simulates the built-in mechanical behaviour of an ETFE foil much more accurately. It is possible to examine the effect of different stress ratios and loading speed and biaxial creep behaviour.

\subsection{The bubble inflation test type}

During bubble inflation tests, different shaped (rectangular, triangular, circular) flat test specimens are clamped between an aluminium or steel ring and plate. Air is blown between the layers generating an internal pressure

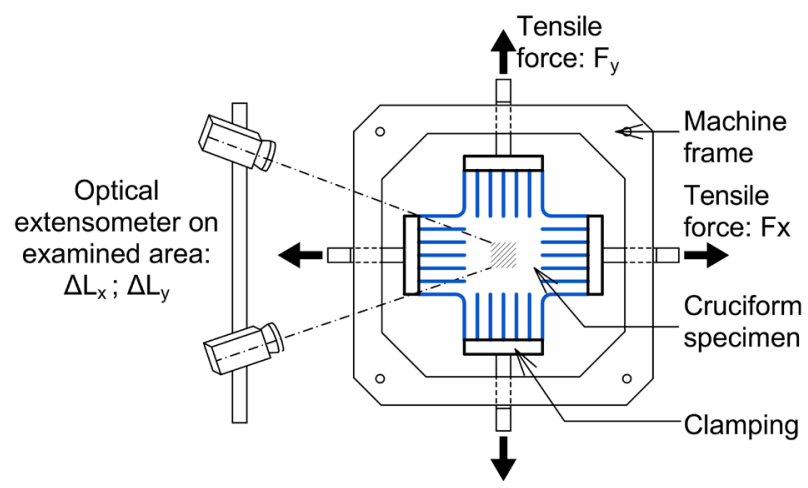

Fig. 4 Schematic drawing of the biaxial tensile test 
resulting in a spherical deformation of the foil (Fig. 5). This measurement uses digital pressure sensors and digital extensometers.

\section{The elastoplastic behaviour}

The mechanical behaviour of ETFE foils is the same as for polymers. It presents high non-linearity with large deformations (Lucas et al., 2007). However, for design purposes, designers consider a linear elastic model with isotropic characteristics based on the initial behaviour. To understand the true elastoplastic material behaviour, Galliot and Luchsinger (2011), Hu et al. (2015), and Zhao and Chen (2021) conducted a comprehensive experiment series to determine the stress-strain curve for small and large strain levels. Galliot and Luchsinger (2011), De Focatiis et al. (2013), and Charbonneau et al. (2014) also investigated direction-dependent behaviour.

\subsection{Stress-strain curves}

Galliot and Luchsinger (2011) investigated the mechanical properties with uniaxial and biaxial tensile and inflated

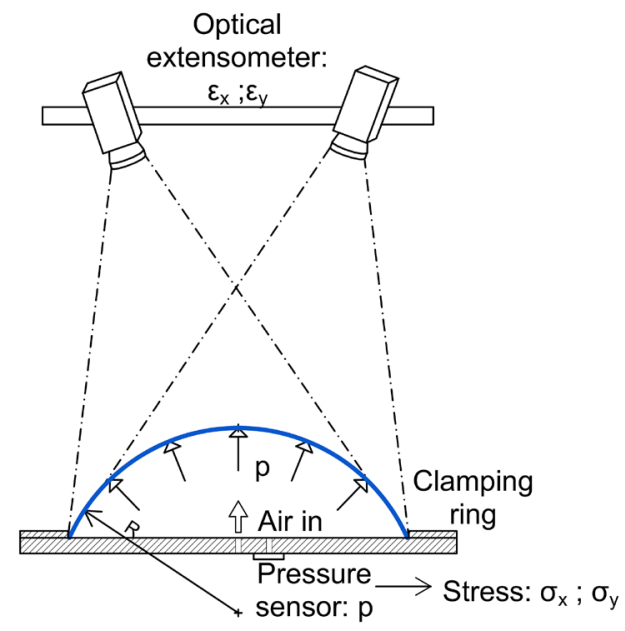

Fig. 5 Schematic drawing of bubble inflation test bubble tests. The uniaxial tensile test was carried out on dogbone-shaped specimens where the engineering stressstrain relation was determined at the central area of the specimen, in M.D., T.D. and $45^{\circ}$ specimen directions under $10 \%$ strain conditions. The typical stress-strain curve can be seen in Fig. 6 .

The curve has three different parts: a linear part and two nonlinear parts. These parts are divided by two yield points at around $2.5 \%$ and $14 \%$ strains. The tensile failure occurred at $300-400 \%$ strain. It is important to note that after the second yield point, the ETFE foil has softening characteristics on the engineering stress-strain diagram. The stress is taken into consideration as a bilinear function of the elongation, and it is fitted to the experimental data. The first yield point is estimated to be at the intersection of two fitted tangent lines fitted on the stress-strain diagram.

Biaxial experiments of Galliot and Luchsinger (2011) showed that the stress ratio does not influence the elastic properties at small strains. All the experimental test data from different test types resulted in similar material characteristics when true stress and strains were used. So, the choice of a test method only depends on its advantages and limitations.

Zhao and Chen (2020) described the same characteristic as above, where the engineering stress-strain relations first deformation stage is viscoelastic, second is viscoelastic-plastic, and the last is extremely viscoplastic with rapid hardening effect. They also describe the tangent, secant and equivalent elastic moduli with polynomial fitting and equivalent energy method.

Hu et al. $(2015,2017)$ proposed a method to calculate the material's elastic modulus and yield stress at small strains. They argued that the small deviation of the existing methods (tangent and secant method) could highly affect the result and introduced a derivative curve of a $3^{\text {rd }}$ order polynomial fitting on the stress-strain curve. Then, the first yield point is considered to be where the average elastic

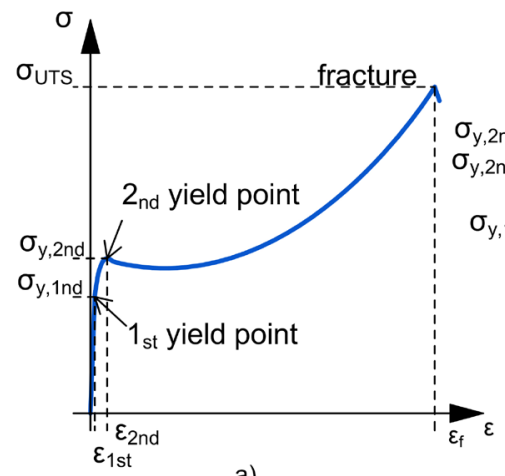

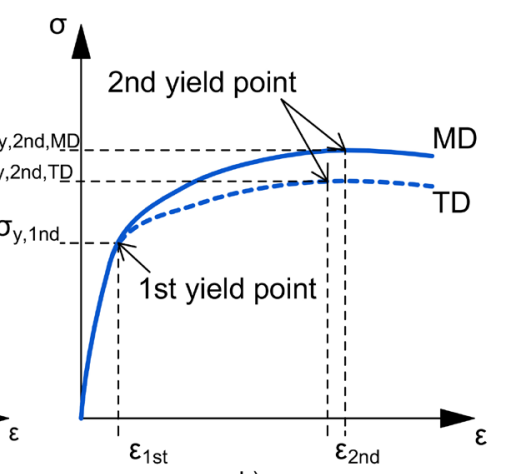

Fig. 6 a) The typical engineering stress-strain curves of ETFE foils under uniaxial loading in one direction; b) The typical engineering stress-strain curve at a smaller strain range 
modulus reaches $70 \mathrm{MPa}$. The paper determined the yield stress based on the loading speed changes with a polynomial equation fitting and setting the yield point with an energy difference of $5 \%$ between the two integral areas on the stress-strain diagram of the uniaxial tensile test.

Fig. 6 shows the typical characteristics of the engineering stress-strain curves of ETFE foils based on the introduced studies in Subsection 4.1.

Table 3 shows the acquired material properties of the papers.

\subsection{Anisotropy of ETFE sheets}

Galliot and Luchsinger (2011) examined the direction dependency of the material at small and large strain levels in uniaxial tensile and bubble inflation tests with a digital extensometer. Their study showed that the ETFE foil is isotropic under small (10\%) strain levels and anisotropic at large strain levels (10-400\%) (Fig. 7).

Charbonneau et al. (2014) found the same as Galliot and Luchsinger (2011) in short (24 hours) and longterm creep (7 days) tests. Different levels of anisotropic behaviour occurred on four different types of material. In specific material types, there were visible differences between the orthogonal directions of measurements. The creep strain speed and material stiffness were higher in the T.D., but the tensile strength was lower than in M.D. at specific materials.

De Focatiis and Gubler (2013) investigated the uniaxial tensile characteristics of extruded films from different manufacturers in both M.D. and T.D. at different temperature and strain rates. They determined the true stress - nominal strain and true stress - true strain diagrams of ETFE

\begin{tabular}{lcccc}
\multicolumn{5}{c}{ Table 3 Material properties of the studies } \\
\hline $\begin{array}{l}\text { Galliot and } \\
\text { Properties } \\
(2011)\end{array}$ & $\begin{array}{c}\text { Zhao and } \\
\text { Chen }(2020)\end{array}$ & $\begin{array}{c}\text { Hu et al } \\
(2015 ; 2017)\end{array}$ & $\begin{array}{c}\text { De Focatiis } \\
\text { and Gubler } \\
(2013)\end{array}$ \\
\hline $\begin{array}{l}\text { Stress } \\
\text { type }\end{array}$ & engineering & engineering & engineering & true \\
$\begin{array}{l}\text { Strain rates } \\
\text { (\%/min) }\end{array}$ & $0.4-2000$ & $1-1000$ & $10-1000$ & $6-6000$ \\
$\begin{array}{l}\text { 1st yield } \\
\text { point } \\
\text { (MPa) }\end{array}$ & $13.5-20$ & $13.5-17.6$ & $13.5-17.6$ & $6-8$ \\
$\begin{array}{l}\text { 2nd yield } \\
\text { point } \\
\text { (MPa) }\end{array}$ & $25-27$ & $20-24$ & & $10-25$ \\
$\begin{array}{l}\text { Elastic } \\
\text { modulus } \\
\text { (MPa) }\end{array}$ & $1000-1200$ & $934-1125$ & $782-1117$ & $350-500$ \\
\hline
\end{tabular}

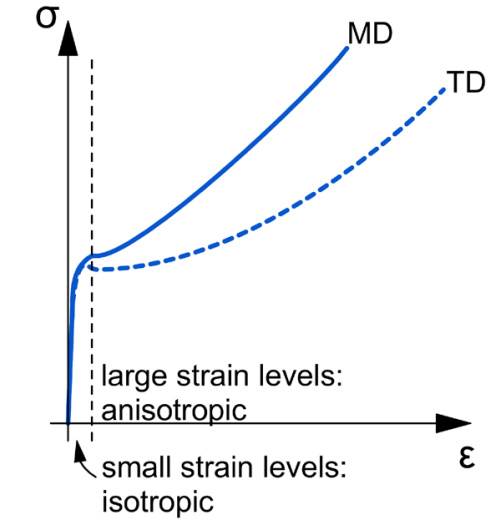

Fig. 7 A typical uniaxial tensile result of ETFE foils in the two perpendicular material directions

where the true stress is defined as the Cauchy stress, the true strain is the natural $\log$ of the quotient of the current length over the original length. They proved that the anisotropy might come from the manufacturing process of ETFE films and the crystalline and molecular structure of the copolymer. During manufacturing, the granules are melted by friction during the extrusion process while they are pushed out into a form through a nozzle. This highly aligns the polymer chains close to the extrusion direction, while the crystalline lamellae and amorphous domains also show anisotropy in the length scale. As discussed in Section 2, the chain bonds are stronger than the intermolecular ones, so the material is stronger parallel to the crystalline chain direction. They suggested representing the anisotropy of the material on true stress - true strain diagrams by horizontal shift with a pre-stretch parameter along the true strain axis:

$\sigma_{T D}(\lambda)=\sigma_{T D}\left(\lambda_{\perp} \lambda\right)$

where $\lambda_{\perp}$ is the value of the pre-stretch chosen in such a way that the shift is $\ln \left(\lambda_{\perp}\right)$.

\section{Viscoelasto-plastic behaviour and the constitutive laws}

ETFE, as a semi-crystallin thermoplastic copolymer, has significant thermo viscoelastic-plastic properties, which might affect the structures made of ETFE in a way that creep and relaxation can result in loss of pre-tension and wrinkles of the surface. Moreover, semicrystalline polymers have a sharp temperature point called glass transition point before the melting point; the absorbed energy converts the material from a glassy state into a rubbery plastic state. The time-temperature superposition principle characterizes these polymers (Williams et al., 1955). Accordingly, the 
mechanical response at a different time or temperature range can be predicted from the so-called W.L.F. equations, which determine simple relations between these data.

For nonlinear thermo viscoelastic-plastic materials, as the ETFE is, there are numerous developed constitutive models. Some of them are continuum-based models describing the material behaviour with single integral formulations (Schapery, 1966, 1969, 1997). Many other developed models are based on the activation energy barriers for polymer networks (Boyce et al., 1988; Bergström and Boyce, 1998; Dupaix and Boyce, 2007). A possible alternative approach for a constitutive model for ETFE is the free volume model of Knauss and Emri (1981) and its updated methods by Kwok and Pellegrino (2012) and Li et al. (2016). Secondly, Drozdov and Christiansen (2007) developed a constitutive model to describe the cyclic viscoplasticity of high-density polymers.

\subsection{Strain rate dependency of ETFE foils}

Galliot and Luchsinger (2011) and $\mathrm{Hu}$ et al. $(2015,2017)$ investigated the material behaviour at different loading speeds at small strain levels for strain rate dependency. Their study showed that the stiffness and yield stresses increase at a higher strain rate (Fig. 8). Galliot and Luchsinger (2011) have also determined that both values increase with linear tendencies as the logarithmic function of the strain rate increases.

They proposed a phenomenological constitutive model to describe strain rate dependency for the finite element method at small strain regions. The viscoplastic material model of Perzyna (1966) was used to describe the strain rate dependency of the material:

$$
\sigma_{\text {yield }}=\left[1+\left(\frac{\dot{\varepsilon}_{\text {plastic }}}{\gamma}\right)^{m}\right] \sigma_{0} \text {, }
$$

where $\sigma_{\text {yield }}$ is the rate-dependent true yield stress, $\sigma_{0}$ is the true yield stress, $\gamma$ is a viscosity parameter, $m$ is a strain

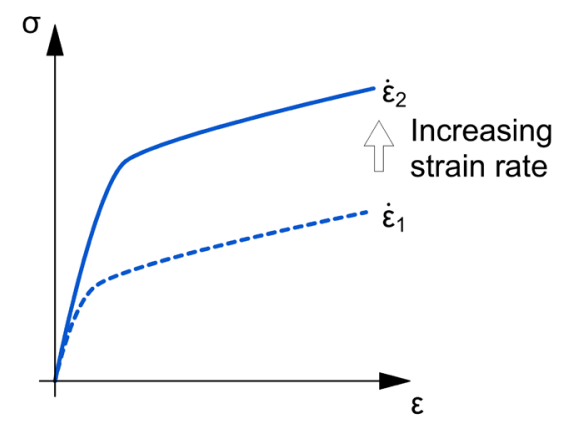

Fig. 8 The typical characteristic of uniaxial stress-strain curves of ETFE foils measured at different strain rates in MD. hardening parameter, $\dot{\varepsilon}_{\text {plastic }}$ is the true plastic strain rate. The authors mentioned that the model is highly approximate because it cannot predict nonlinear viscous behaviour.

However, Hu et al. (2015) showed that the linear approach has some deviation from the acquired data, which results in minor inaccuracies in the model of Galliot and Luchsinger (2011). Their first phenomenological model homogenizes the material structure as an incompressible medium and describes the viscoelastic-plastic constitutive model based on Drozdov's theory (Drozdov and Christiansen, 2007). The basis of the theory is the separation of the total deformations of the semicrystalline material into non-zero elastic and plastic components and the separation of the plastic component into crystalline and amorphous deformation parts. The strain energies of each component can be determined from the momentum balance law, the two laws of thermodynamics and the Clausius-Duhem inequality:

$$
\sigma(t)=\mu(1-\phi(t))\left[\begin{array}{l}
\varepsilon_{e}-\int_{0}^{\infty} f(v) \int_{0}^{t} \Gamma(\tau, v) . \\
\exp \left(\int_{\tau}^{t} \Gamma(s, v) d s\right) \times \varepsilon_{e}(t) d \tau d v
\end{array}\right],
$$

where $\mu$ is the elastic modulus obtained from the tests, $\varphi(t)$ is a non-negative function for the description of the strain in a crystalline state, and it is governed by a differential equation based on adjustable material parameters, $\varepsilon_{e}$ is the strain tensor for elastic strains, $f(v)$ is the function from the random energy model proposed by Derrida (1980) (it can describe a disordered system whose energy levels are independent random variables), $\Gamma$ is the Eying equation (Nanzai, 1990) which governs the rate of separation of active polymer in a meso-domain, $v$ is the activation energy for the rearrangement, $t$ is time, $\tau$ is the time when the temporary network of chains return into an active state.

Zhao and Chen (2020) uniaxial tests results showed a nonlinear characteristic for all material properties. To capture this nonlinear strain rate dependency of material parameters, exponential functions Eqs. (4-5) were used with three material parameters:

$$
\left\{\begin{array}{l}
\sigma_{y, \mathrm{f}^{\mathrm{st}}}=\exp \left(2.91-\frac{58.79}{\dot{\varepsilon}+200.87}\right) \\
\sigma_{y, 2^{\mathrm{nd}}}=\exp \left(3.24-\frac{126.01}{\dot{\varepsilon}+556.04}\right) \\
\sigma_{u}=\exp \left(3.85-\frac{5.58}{\dot{\varepsilon}+58.12}\right)
\end{array}\right.
$$




$$
\left\{\begin{array}{l}
\varepsilon_{y, \mathrm{I}^{\mathrm{tt}}}=\exp \left(1.21-\frac{82.22}{\dot{\varepsilon}+145.01}\right) \\
\varepsilon_{y, 2^{\mathrm{nd}}}=\exp \left(2.89-\frac{40.25}{\dot{\varepsilon}+299.05}\right), \\
\varepsilon_{u}=\exp \left(6.03+\frac{3.38}{\dot{\varepsilon}+33.34}\right)
\end{array}\right.
$$

where $\sigma_{y, 1^{\mathrm{st}}} ; \sigma_{y, 2^{\mathrm{nd}}} ; \sigma_{u}$ are the first yield stress, second yield stress and ultimate stress, respectively; $\varepsilon_{y, 1^{\mathrm{s}}} ; \varepsilon_{y, 2^{\text {nd }}} ; \varepsilon_{u}$ are the first yield strain, second yield strain and ultimate strain respectively; $\dot{\varepsilon}$ is the loading strain rate. Based on their preliminary observation, a $3^{\text {rd }}$ order polynomial function system clearly describes the tangent, secant and equivalent elastic modulus. Eq. (6):

$$
\left\{\begin{array}{l}
E_{t}=0.038 \dot{\varepsilon}^{3}+1.41 \dot{\varepsilon}^{2}+1.57 \dot{\varepsilon}+935.1 \\
E_{s}=0.651 \dot{\varepsilon}^{3}-10.1 \dot{\varepsilon}^{2}+55.3 \dot{\varepsilon}+585.7 \\
E_{e}=0.3 \dot{\varepsilon}^{3}-3.47 \dot{\varepsilon}^{2}+24.4 \dot{\varepsilon}+785.5
\end{array}\right.
$$

The material parameters were determined by leastsquares minimization.

The presented study of Zhao and Chen (2020) also proposed a rheological constitutive model for uniaxial monotonic tensile. The base of their model is the generalized Maxwell model, where a spring element and several basic Maxwell elements are connected in parallel, which accurately simulates the relaxation of material at fixed strain (Fig. 9).

The model takes into consideration the Boltzmann superposition principle, where the total creep strain is the function of its total loading history divided into multiple loading steps, and the sum of deformation at each step gives the final deformation. Thus, the superposition of numerous strains through time can be considered generally as a continuous differentiable function. To obtain the constitutive model, Zhao and Chen (2020) considered

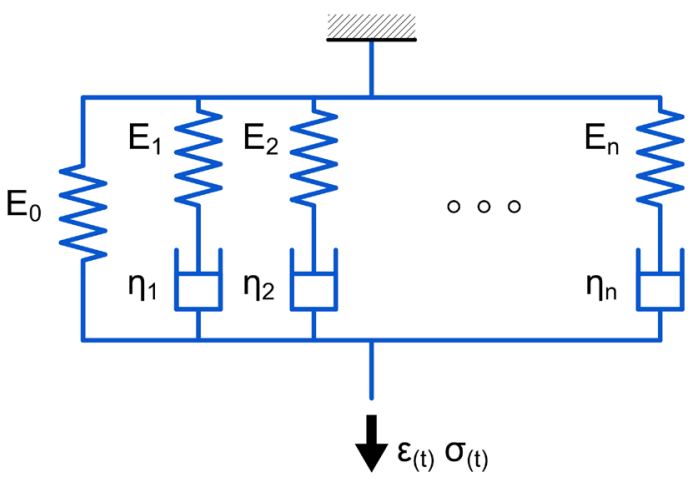

Fig. 9 Schematics of the generalized Maxwell model used in the study of Zhao and Chen (2020) the Generalized Maxwell model and the Boltzmann superposition principle in the following form:

$\sigma(t)=\varepsilon_{0} G(t)+\int_{0}^{t} G(t-\zeta) \frac{d \varepsilon(\zeta)}{d \zeta} d \zeta$,

where $\sigma(t)$ is the total stress, $\varepsilon_{0}$ is the strain on the end of the basic spring element, $G(t)$ is the relaxation elastic modulus of the generalized Maxwell model at $t=0, t$ is the overall time and $\zeta$ is an integrand variable for the time. Through expressing the total strain as the function of the strain rate, time and the initial strain, the paper proposed the following constitutive equation (Eq. (8)):

$\sigma(t)=E_{0} \varepsilon(t)+\dot{\varepsilon} \sum_{i=1}^{n} \eta_{i}\left(1-e^{\frac{\varepsilon(t)}{\dot{\varepsilon} \tau_{i}}}\right)$

where $E_{0}$ denotes the total stress increasing rate of the stable basic Maxwell model, $\varepsilon(t)$ is the total strain, $\dot{\varepsilon}$ is the strain rate of the test, $\eta_{i}$ and $\tau_{i}$ are the viscosity coefficients and relaxation time coefficient of the $i$-th dashpot element in the Maxwell model, respectively. From the previously detailed constitutive relation, the paper reports a five and a seven parameter model to describe the first $15 \%$ and $30 \%$ strain stage, respectively, given as:

$$
\begin{aligned}
& \sigma(t)=E_{0} \varepsilon(t)+\dot{\varepsilon} \eta_{1}\left(1-e^{\frac{\varepsilon(t) E_{1}}{\dot{\varepsilon} \eta_{1}}}\right)+\dot{\varepsilon} \eta_{2}\left(1-e^{\frac{\varepsilon(t) E_{2}}{\dot{\varepsilon} \eta_{2}}}\right), \\
& \sigma(t)=E_{0} \varepsilon(t)+\dot{\varepsilon} \eta_{1}\left(1-e^{\frac{\varepsilon(t) E_{1}}{\dot{\varepsilon} \eta_{1}}}\right) \\
& +\dot{\varepsilon} \eta_{2}\left(1-e^{\frac{\varepsilon(t) E_{2}}{\dot{\varepsilon} \eta_{2}}}\right)+\dot{\varepsilon} \eta_{3}\left(1-e^{\frac{\varepsilon(t) E_{3}}{\dot{\varepsilon} \eta_{3}}}\right) .
\end{aligned}
$$

\subsection{Creep behaviour}

Charbonneau et al. (2014) investigated by uniaxial tensile tests the short- $(24 \mathrm{~h})$ and long-term (7-day) creep behaviour on rectangular test specimens in M.D. and T.D. at constant temperature $\left(23^{\circ} \mathrm{C}\right)$ with four different foil types at different stress levels from 2 to $14 \mathrm{MPa}$. They have reported that the thinner the material was, the smaller the creep strains were. First of all, the creep strains increased from 0.001 to $0.05 \mathrm{~mm} / \mathrm{mm}$ with increasing stress levels; secondly, the higher the stress level was, the more differences there were between the curves of M.D. and T.D. (Fig. 10). Products of different manufacturers and different material directions also resulted in differences in the creep strains. The authors proposed two constitutive 


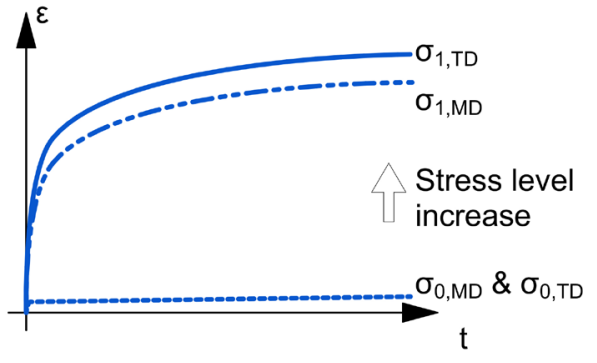

Fig. 10 Typical viscoelastic curves of ETFE foils for a day-long creep test

models to describe the creep phenomena of ETFE membranes as viscoelastic materials.

The first model to capture their experiments short time creep data describes a modified multi-Kelvin model formulated by Liu (2007) with spring element for elastic response and Kelvin elements in series for the viscous response. The creep compliance $\psi(t)$ is:

$\psi(t)=\frac{1}{E_{0}}+\sum_{i=1}^{N} \frac{1}{E_{i}}\left[1-\exp \left(\frac{-t}{\tau_{i}}\right)\right]$,

where $E_{0}$ is the elastic modulus of the linear section of the material, $t$ is the time of loading, $i$ is the index value denoting the $i$-th Kelvin spring stiffness $E_{i}$ and relaxation time $\tau_{i} . N$ is the number of Kelvin elements. For numerical analysis, a four Kelvin element model was defined at different relaxation times.

The second material model to capture their experiments long time creep data is a power function:

$\psi(t)=\frac{1}{E_{0}}+C_{0} t^{C_{1}}$

where $\psi(t)$ and $E_{0}$ is detailed above, $C_{0}$ and $C_{1}$ are material constants determined by linear least-squares from the creep curves. The paper reports that the multi-Kelvin model converges to a constant value in time, accurate only for long-time creep. However, the power-function model describes short time creep better.

Li and $\mathrm{Wu}$ (2015) investigated short-term (24 h) creep and recovery tests on rectangular-shaped 150 by $50 \mathrm{~mm}$ specimens. Different stress levels were used: $3,6,8 \mathrm{MPa}$ with different temperatures: $23,28,35,41,46,51^{\circ} \mathrm{C}$. The stress-related creep behaviour does not show significant differences from the results of Charbonneau et al. (2014); however, their study shows a high residual strain of specimens in the recovery test, mostly at high temperature levels (Fig. 11).

The importance of this study was that the 400 day-long

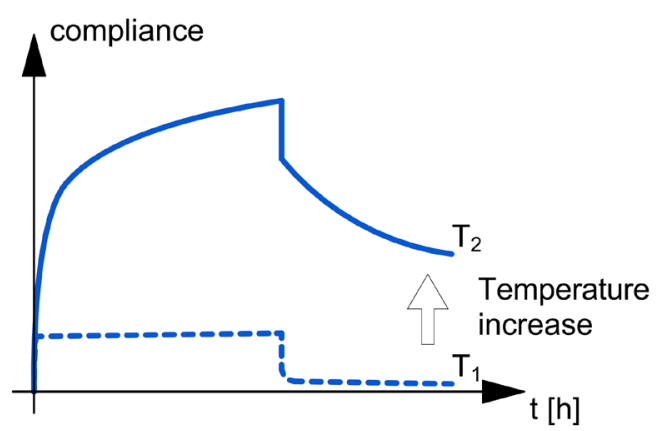

Fig. 11 The $24 \mathrm{~h}$ creep test compliances with the recovery phase at different temperature rates

creep test was also made with identical specimen parameters for short-term creep tests. It is important to note that their study also showed that the time-temperature superposition with the W.L.F. equations applies to ETFE membranes to describe the long-term creep behaviour by shifting creep curves at a different temperature to a master creep curve at the reference temperature.

The paper proposed a viscoelastic-plastic model to describe the observed creep and recovery behaviour. They characterize the membrane material with the modified generalized Kelvin model by adding a dashpot component to represent viscoplastic behaviour (Fig. 12).

Schapery's nonlinear method (Schapery, 1969) for the viscoelastic behaviour of polymers were adopted. The method differentiates the total strain into elastic initial $\left(\varepsilon_{0}\right)$, viscoelastic $\left(\varepsilon_{v e}\right)$ and viscoplastic $\left(\varepsilon_{v p}\right)$ strains:

$\varepsilon_{c}(t)=\varepsilon_{0}+\varepsilon_{v e}(t)+\varepsilon_{v p}(t)$,

from which the creep and recovery equation can be expressed:

$$
\begin{aligned}
\varepsilon_{c}(t) & =\left[g_{0} D_{0}+g_{1} g_{2} \sum_{r=1}^{N} D_{r}\left(1-e^{-\frac{t}{10^{r}}}\right)+g_{1} D_{s} t^{n}\right] \sigma_{c}, \\
& \leq t \leq T,
\end{aligned}
$$

$\begin{aligned} \varepsilon_{r}(t) & =\left[\varepsilon_{c}(T)-g_{0} D_{0}-g_{1} g_{2} \sum_{r=1}^{N} D_{r}\left(1-e^{-\frac{t-T}{10^{r}}}\right)\right] \sigma_{c}, \\ T & <t \leq 2 T,\end{aligned}$

where $T$ is the cycle of creep and recovery behaviours, $\varepsilon_{0}$ is the initial strain $\varepsilon_{v e}(t)$ is the viscoelastic creep strain, $\varepsilon_{v p}(t)$ is the viscoplastic creep strain, $N$ is the number of Kelvin components, $D_{r}$ is the coefficients of the Kelvin model, $\tau_{r}$ is the retarded time in the generalised Kelvin model $D_{s}$ is the coefficient for the dashpot, $n$ is the material constant of the dashpot. In the physical model, the spring and its initial compliance appear in the first term. The Kelvin model fully 


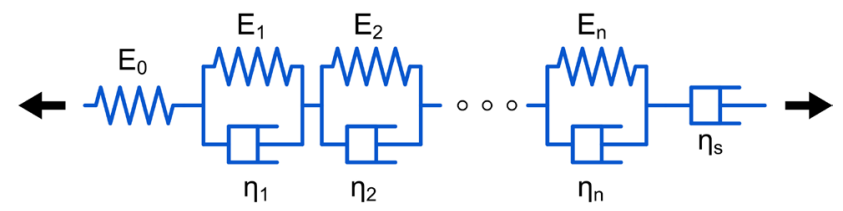

Fig. 12 The schematics of the physical model proposed by $\mathrm{Li}$ and $\mathrm{Wu}$, (2015) for the revised creep equations of ETFE foil. The physical model comprises a spring, a multi-Kelvin and a dashpot.

recoverable transient compliance component appears in the second term, and the unrecoverable strains represented by the dashpot appear in the third term as a revised power law. The model was validated with a high precision overlap on the short time creep and recovery test described above. The paper also reports that this model, with the supplemented steady flow component, models the viscoelastic-plastic creep behaviour more accurately than the traditional generalized Kelvin model.

The paper reports a model for the long-term creep behaviour, which is predicted with the help of the time-temperature shift described in Section 4. Through shifting creep curves at different temperatures (Moritz, 2009), the obtained shifting factor W.L.F. equations is:

$$
\log a_{T}=\log a_{\text {Tref }}+\phi_{\text {Tref }}=\frac{-17,44\left(T-T_{\text {tran }}\right)}{51,6+T-T_{\text {tran }}},
$$

where $\log a_{\text {Tref }}$ is the horizontal shifting factor from the reference temperature $T_{\text {ref }}$ to the transition temperature $T_{\text {tran }}$. The model validity shows that if all the measurements were carried out and shifted to identical temperature, the prediction curve of the model follows it quite well; however, the short-term creep model at identical temperature was insufficient to model the long-term creep.

Coelho and Roehl (2015) proposed a continuum mechanical description for the numerical simulations of bursts tests with the viscoelastic-plastic behaviour of ETFE considering plane stress state. They model the total strain deformations as a combination of finite elastic and finite plastic strains based on the finite strain theory, according to Lee and Liu (1967). The stretch tensor and second Piola-Kirchoff stress tensor are used in the Lagrangian coordinate system, and for the formulation, the authors propose an algorithm based on Simo and Taylor (1986); Simo and Hughers (1998) and de Souza Neto et al. (2008) with a linear elastic constitutive law:

$$
\begin{aligned}
& \dot{\boldsymbol{S}}=\boldsymbol{D}:\left(\dot{\boldsymbol{E}}-\dot{\boldsymbol{E}}^{v p}\right), \\
& D=\frac{E}{1-v^{2}}\left[\begin{array}{ccc}
1 & v & 0 \\
v & 1 & 0 \\
0 & 0 & \frac{1-v}{2}
\end{array}\right],
\end{aligned}
$$

where $\dot{\boldsymbol{S}}$ is the second Piola-Kirchoff stress tensor, $\boldsymbol{D}$ is the elastic constitutive material tensor for small strains, $\dot{\boldsymbol{E}}$ is the Green-Lagrange strain tensor rate and $\dot{\boldsymbol{E}}^{v p}$ is the plastic strain rate described by the Perić model (de Souza Neto et al., 2008), $v$ is the Poisson modulus, and $E$ is Young's modulus. Cabello and Bown (2019) proposed a nonlinear thermo-viscoelastic constitutive model for small and large strain levels derived from thermodynamic principles by Schapery (1969) and Rand et al. (1996). It models the nonlinear viscoelastic behaviour by combining a linear viscoelastic model with the free volume theory of Knauss and Emri (1981) and Li et al. (2016). The free volume theory postulates a relation between the macroscopic, thermoviscoelastic behaviour of films and their free volume during deformation; hence it influences the time shift factor.

The compliance matrix is determined as:

$$
D(t)=\left[\begin{array}{cclr}
D_{11}(t) & D_{12}(t) & D_{13}(t) & 0 \\
D_{12}(t) & D_{22}(t) & D_{23}(t) & 0 \\
D_{13}(t) & D_{23}(t) & 0 & 0 \\
0 & 0 & 0 & D_{13}(t)
\end{array}\right]
$$

where 1, 2 denote the in-plane compliance terms for MD and TD, 3 denote the out-of-plane compliance terms, and 6 denote the in-plane shear compliance component. Each term can be represented by a Prony series:

$D_{i j}(t)=D_{i j, 0}+\sum_{k=1}^{n} D_{i j, k}\left(1-e^{-t / \tau_{k}}\right)$

where $D_{i j, 0}$ is the elastic compliance for $t=0 ; D_{i j, k}$ are the Prony coefficients, $\tau_{\kappa}$ is the retardation time corresponding to the kth element. The time shift factor in the nonlinear case is modified by the dilatational, shearing, deformation (Popelar and Liechti, 1997, 2003) and assumed to be related to the fractional volume (Doolittle, 1951):

$$
\log a=-\frac{B}{2.303 f_{0}}\left(\frac{\alpha_{v}\left(T-T_{0}\right)+\delta_{v} \cdot \theta+\delta_{s} \cdot \epsilon_{e f f}}{f_{d}+\alpha_{v}\left(T-T_{0}\right)+\delta_{v} \cdot \theta+\delta_{s} \cdot \epsilon_{e f f}}\right),
$$

where $\log a$ is the shift factor value, $B$ is a material parameter, $f_{0}$ is the fractional volume in the unstressed material at $T_{0}$ temperature reference condition, $a_{v}$ is the volumetric coefficient of thermal expansion, $\theta$ is the mechanical dilatation, $\delta_{v}$ is a material constant that relates changes in mechanical dilatation to changes in free volume, $\delta_{s}$ relates changes in effective deviatoric strain to changes in free volume, $\epsilon_{\text {eff }}$ is the effective deviatoric strain. 


\subsection{Cyclic behaviour}

To determine a true yield stress value, Hu et al. (2014) made cyclic uniaxial tensile tests on dogbone shape specimens in eight loading level groups. During the test, the engineering stress-strain relation was investigated on a $6 \mathrm{~mm}$ by $25 \mathrm{~mm}$ area in the centre of specimens at $5 \mathrm{~mm} / \mathrm{min}$ loading rate at $24^{\circ} \mathrm{C}$. The paper differentiates the elastic modulus for the loading and unloading parts of the hysteresis curve. Both values remained similar during the cycles because of the microstructural build-up of the material (Tanigami et al., 1986); however, the unloading elastic moduli were greater than the loading elastic moduli due to the viscoelastic-plasticity irreversible strains. The paper determined the elastic moduli of the first loading and the unloading by the least squares method fitting linear curves on different parts of the test results. They realized that due to the strain hardening effect of polymers (Tanigami et al., 1986; Zhang and Moore, 1997), the yield occurs at an approximately constant strain level of $2.3 \%$, but the value of the yield stress is increasing with a higher loading stress.

\section{The failure of the ETFE}

The analysis of failure mechanics of polymers is a relatively new and active area of material science today. The detailed polymer microstructure and the viscoelastic-plastic material properties in Sections 2-5 highly affect the fracture behaviour of polymers, thus also the fracture of ETFE. Compared to many plastics, the toughness of semicrystalline thermoplastics is typically higher at room temperature, and the failure forms at the macroscopic level can be tearing, shear and plastic yielding (Hertzberg et al., 2012). The basic crack type of plastics is ductile fracture, and a complex crack evolution characterizes the polymers failure phenomena (Hertzberg et al., 2012). The fracture starts at the atomic level with the debonding of the molecular chains (Van der Waals bonds), leading to the formation of fibrils and cavitation during cracks. These form a highly localized deformation region called crazes at the crack tip, which only occurs under tension, and is analogous to the necking zone during ductile yielding. Although the fibrils carry most of the stress due to the stronger covalent bonds in the structure, the failure process is also altered by the greater plastic deformation zone around the crack tip from the further debonding of molecules (Kusoglu et al., 2011) (Fig. 13).

To provide the fracture toughness of polymers such as ETFE, nonlinear fracture mechanics should be used because of the raised large-plastic zone around the crack tip of the specimens. Even though numerous approaches

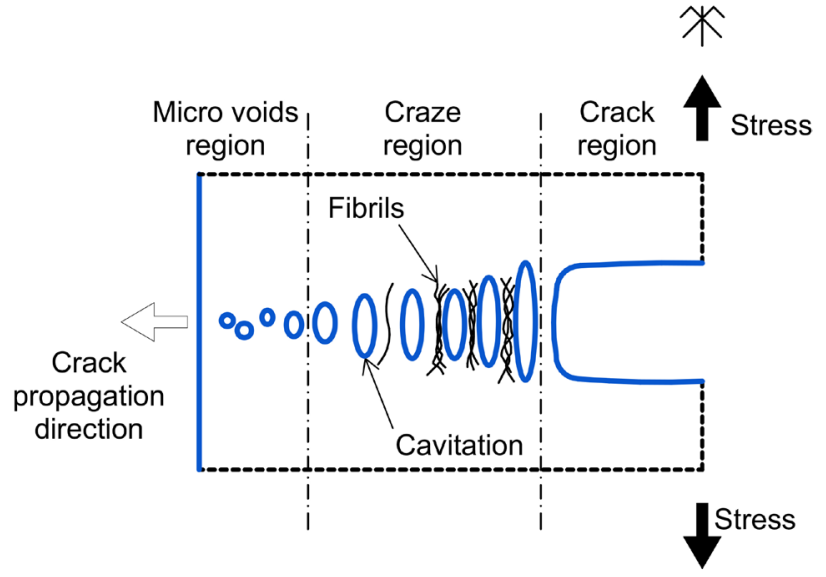

Fig. 13 An illustration of craze formation and growth with fibrillation, void formation, and nucleation

exist, which can effectively handle these phenomena during loading, mostly the J-integral (Hegyi and Pellegrino, 2015; Rice, 1968) and the essential work of fracture (EWF) (Bárány et al., 2003) theory are used widely for polymers. The manufacturing also affects the molecular structure and the failure behaviour (sequential drawing lines result in aligned molecular orientation while simultaneous drawing results in radial molecular orientation).

\subsection{Tensile strength of ETFE}

Galliot and Luchsinger (2011) obtained that, at normal temperature $\left(23^{\circ} \mathrm{C}\right)$ and strain rate $(100 \% / \mathrm{min})$, the tensile strength is approximately $55 \mathrm{Mpa}$, and the elongation of the breaking is at cca. $400 \%$ (Fig. 6). They also claimed that the conventional biaxial measurements cannot correctly measure the tensile strength because the arms are in a uniaxial stress state due to the higher strains than the central part.

Lee and Shon (2013) investigated ETFE in the uniaxial tensile test in both directions and at different temperatures from 23 to $100{ }^{\circ} \mathrm{C}$. They reported that the strength is decreasing with increasing temperature, and the elongation is increasing with no observable differences in the directions.

Charbonneau et al. (2014) made uniaxial and biaxial tensile tests on different films in M.D. and T.D. of ETFE foils at standard test configurations. They have observed that in two different film cases, the tensile strength was different between the two directions. In M.D., it was approximately $69 \mathrm{MPa}$ at $363-388 \%$ strain while in T.D. $50-57 \mathrm{MPa}$ at $455-501 \%$ strains. However, in the case of a different foil type, there were no differences between the two directions, the tensile strength was significantly lower, an average of 46 MPa with 578\% strains. This might result from the molecular properties of the foils, as detailed previously, but the manufacturer did not provide these properties for the resin. 


\subsection{Fracture mechanics of ETFE}

Uehara et al. (2015) investigated the tensile strength and tear resistance of ETFE membranes in terms of molecular crystalline alignment. In their study, they made biaxial tensile measurements with a small-angle X-ray scattering method on laminates consisting of low and high molecular weighted ETFE membrane layers. The fracture mechanism was investigated in the middle of the specimen with two semicircular notches on the sides at the longitudinal centre (He et al., 2014). With in situ X-ray scattering, it is possible to detect the destructing crystalline and amorphous components in the phase arrangement. It is assumed that tensile strength is higher with a higher portion of parallel lamellae along the membrane surface with matching testing directions. In contrast, the tear strength is higher with a higher portion of initially inclined lamellae, effectively absorbing stress during tearing.

The result of the X-ray scattering indicates the polymer lamellae direction. The circular pattern shows homogeneous (parallel and inclined) lamellae distribution, while the lozenge pattern indicates more load parallel lamellae in the membrane. It is important to note that during the deformation of the membrane, the rate of the inclined and parallel lamellae is changing, and it seems to be irreversible with unloading. This study proved the molecular background of the anisotropic and strain-dependent mechanical behaviour of the material.

Zhao et al. (2017) have mainly studied the general mechanical behaviour and the failure modes of ETFE cushion with a pressure control system during wind load simulation tests at different temperature levels of $-50{ }^{\circ} \mathrm{C},-25^{\circ} \mathrm{C}$ and $0{ }^{\circ} \mathrm{C}$. The results showed slits in the middle region of the inner layers seams. The length of the slit and speed of the spreading was faster at smaller environmental temperature, indicating brittle failure under $0{ }^{\circ} \mathrm{C}$.

Rigotti et al. (2019) studied the strain-rate and temperature-dependent fracture properties of ETFE with the essential work of the fracture method. In their study, double-edge notched (DENT) ETFE strips were tested with different ligament lengths $(7.9,11,13,15 \mathrm{~mm})$ based on ESIS TC4 testing protocols (Clutton, 2000) to stay in plane-stress conditions (Fig. 14).

Based on the EWF approach, the total energy of the fracture on a DENT specimen can be divided into two parts, namely the essential and the non-essential work of fracture. The essential work of fracture is the energy consumed by the fracture possession zone, and it is proportional to the ligament area. In contrast, the non-essential

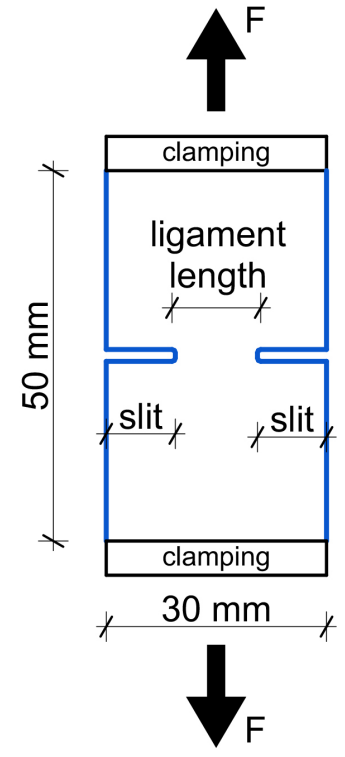

Fig. 14 A schematic drawing of a DENT specimen

work of fracture is the dissipated energy in the outer plastic zone of the crack, which is proportional to the volume of the plastic region. From these terms, the specific work of fracture can be acquired, which is the total work of fracture divided by the ligament length:

$$
\begin{aligned}
& w_{f}=W_{f} / t L=w_{e}+\beta w_{p} L=w_{\text {init }}+w_{\text {prop }}, \\
& w_{e}=W_{e} / t L, \\
& w_{p}=W_{p} / t L^{2}, \\
& w_{\text {init }}=w_{e, \text { init }}+\beta^{\prime} w_{p, \text { init }} L, \\
& w_{\text {prop }}=w_{e, \text { prop }}+\beta^{\prime} w_{p, \text { prop }} L,
\end{aligned}
$$

where $w_{e}$ is the specific essential work of fracture, $w_{p}$ is the specific non-essential work of fracture, $t$ is the thickness of the specimen, $L$ is the ligament length, $\beta$ is the plastic zone shape factor, $w_{\text {init }}$ is the specific work for crack initiation and $w_{\text {prop }}$ is the specific work for crack propagation. The paper determined the total work of fracture $W_{f}$ from the area under the load-displacement curve while the specific work of fracture was plotted against the ligament length (Fig. 15).

The $w_{e}$ and $w_{p}$ can be determined from the total specific work of fracture versus ligament length diagram where $w_{e}$ is the fitted line value at zero ligament length and $w_{p}$ is the slope of the line. $\beta$ shape factor is determined from the yield zone area from DIC (Digital Image Correlation) measurements against the square of the ligament length plots regression line slope. The specific work for crack initiation 


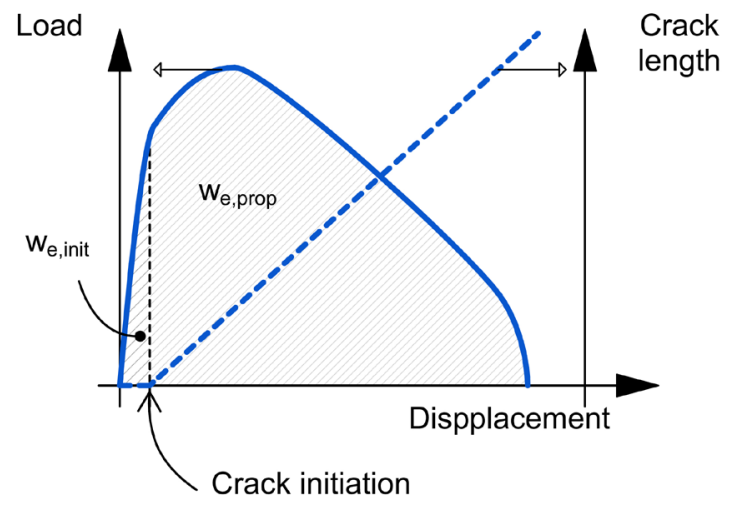

Fig. 15 The typical load-displacement curve (blue) and evolution of the crack length (blue dashed) during the fracture tests of ETFE specimen tested at standard temperature based on the results of Rigotti et al. (2019).

and propagation is determined from the areas under the load-displacement diagram (continuous) from the tensile machine and the load-crack length diagrams (Fig. 15).

The load-displacement diagram can be separated into two parts based on the crack-onset point on the load-crack length diagram. The first part starts with the experiment and ends with the start of the crack initiation. Then the second part ends with the end of the experiment. The area under the load-displacement for the first and second part is the $w_{e, \text { init }}$ and $w_{e, p r o p}$, respectively.

The paper determines two competing phenomena from the essential work of fracture values plotted against the strain rate. At room temperature, $w_{e}$ increased as the strain rate increased, while at a higher temperature, it decreased due to the strain rate embrittlement effect (Chen et al. 2004). This was proven by infrared images, which showed the higher temperature at crack tips, which could increase the mobility of the polymer chains orientation as thus the fracture toughness. The shape of the outer plastic zone (OPZ) is also determined as an ovoid shape, and it indicates that OPZ increases linearly with the square of the ligament length. This can also help to determine the J-integral of the material in further research.

\section{References}

Bárány, T., Czigány, T., Karger-Kocsis, J. (2003) "Essential work of fracture concept in polymers", Periodica Polytechnica Mechanical Engineering, 47(2), pp. 91-102. [online] Available at: https:// pp.bme.hu/me/article/view/1381 [Accessed: 23 March 2021]

Bergström, J. S., Boyce, M. C. (1998) "Constitutive modeling of the large strain time-dependent behavior of elastomers", Journal of the Mechanics and Physics of Solids, 46(5), pp. 931-954. https://doi.org/10.1016/S0022-5096(97)00075-6

Boyce, M. C., Parks, D. M., Argon, A. S. (1988) "Large inelastic deformation of glassy polymers. part I: rate dependent constitutive model", Mechanics of Materials, 7(1), pp. 15-33. https://doi.org/10.1016/0167-6636(88)90003-8

\section{Conclusions}

This paper summarized available articles about the viscoelastic-plastic characteristic material behaviour, constitutive models and the failure of ETFE membranes. The mechanical properties, such as the typical stress-strain curve, time-dependent and failure properties of the material show the basic characteristics of membranes from semicrystalline polymers. Up to the second yield point, the mechanical response is well examined, and based on the studies, it is almost independent of the manufacturer. The results of the available papers fall into the same ranges; thus, the existing results can be effectively used to validate further research. It is important to note that the orientation of crystalline regions on the micro-level in the membrane greatly influences the mechanical behaviour based on the characteristics of stress-strain diagrams in different load directions and results of the X-ray scattering images during fracture propagation. Several different phenomenological, rheological and continuum material models describe the time-dependent behaviour at different strain rates or time intervals for different purposes. Some of them can effectively unify the time and temperature-dependent responses of the material, although most of the proposed models only capture the mechanical behaviour at small strain regions or requires high numbers of material parameters. However, the ETFE foils have a significant temperature-dependent behaviour; thus, the nonlinear thermo-viscoelastic constitutive model with the free volume theory of Cabello and Bown (2019) have the greatest significance because it effectively captures the material behaviour at different temperature levels and time lengths at the same time. The fractural mechanical investigation of ETFE is a relatively new area, with the existing methods showing promising results. However, further investigation is necessary to properly understand the mechanism of the failure and determine important fractural mechanical parameters for ETFE foils such as J-integral.

Cabello, A., Bown, A. C. (2019) "Using a nonlinear thermo-viscoelastic constitutive model for the design and analysis of ETFE structures", In: Proceedings of the IASS Annual Symposium 2019 - Structural Membranes 2019, Barcelona, Spain, pp. 1-18. [online] Available at: https://www.researchgate.net/publication/335528064_Using_a_nonlinear_thermo-viscoelastic_constitutive_model_for_the_design_and analysis_of_ETFE_structures [Accessed: 23 March 2021]

Charbonneau, L., Polak, M. A., Penlidis, A. (2014) "Mechanical properties of ETFE foils: Testing and modelling", Construction and Building Materials, 60, pp. 63-72. https://doi.org/10.1016/j.conbuildmat.2014.02.048 
Chen, H., Karger-Kocsis, J., Wu, J. (2004) "Effects of molecular structure on the essential work of fracture of amorphous copolyesters at various deformation rates", Polymer, 45(18), pp. 6375-6382. https://doi.org/10.1016/j.polymer.2004.07.007

Clutton, E. Q. (2000) "ESIS TC4 experience with the essential work of fracture method", In: Williams, J. G., Pavan, A. (eds.) European Structural Integrity Society. Elsevier, Elsevier, pp. 187-199. https://doi.org/10.1016/S1566-1369(00)80018-7

Coelho, M.,Roehl, D. (2015) "Elasto-viscoplastic material model considering large strains for ETFE-Foils", In: Proceedings of the VII International Conference on Textile Composites and Inflatable Structures Structural Membranes 2015. VII International Conference on Textile Composites and Inflatable Structures (MEMBRANES 2015), Barcelona, Spain, pp. 201-211. [online] Available at: http://hdl.handle.net/2117/109338 [Accessed: 22 March 2021]

De Focatiis, D. S. A.,Gubler, L. (2013) "Uniaxial deformation and orientation of ethylene-tetrafluoroethylene films", Polymer Testing, 32(8), pp. 1423-1435.

https://doi.org/10.1016/j.polymertesting.2013.09.007

Derrida, B. (1980) "Random-Energy Model: Limit of a Family of Disordered Models", Physical Review Letters, 45(2), pp. 79-82. https://doi.org/10.1103/PhysRevLett.45.79

Doolittle, A. K. (1951) "Studies in Newtonian Flow. II. The Dependence of the Viscosity of Liquids on Free-Space", Journal of Applied Physics, 22(12), pp. 1471-1475.

https://doi.org/10.1063/1.1699894

Drozdov, A. D., Christiansen, J. de C. (2007) "Cyclic viscoplasticity of high-density polyethylene: Experiments and modeling", Computational Materials Science, 39(2), pp. 465-480. https://doi.org/10.1016/j.commatsci.2006.07.014

Dupaix, R. B., Boyce, M. C. (2007) "Constitutive modeling of the finite strain behavior of amorphous polymers in and above the glass transition", Mechanics of Materials, 39(1), pp. 39-52. https://doi.org/10.1016/j.mechmat.2006.02.006

Ebnesajjad, S. (2013) "Introduction to Fluoropolymers", In: Ebnesajjad, S. (ed.) Introduction to Fluoropolymers. Materials, Technology and Application, Elsevier, pp. 63-89. [online] Available at: https://linkinghub.elsevier.com/retrieve/pii/C20120061844 [Accessed: 22 March 2021]

Galliot, C., Luchsinger, R. H. (2011) "Uniaxial and biaxial mechanical properties of ETFE foils", Polymer Testing, 30(4), pp. 356-365. https://doi.org/10.1016/j.polymertesting.2011.02.004

He, G., Li, J., Zhang, F., Lei, F., Guo S. (2014) "A quantitative analysis of the effect of interface delamination on the fracture behavior and toughness of multilayered propylene-ethylene copolymer/ low density polyethylene films by the essential work of fracture (EWF)", Polymer, 55(6), pp. 1583-1592. https://doi.org/10.1016/j.polymer.2014.01.039

Hegyi, D., Pellegrino, S. (2015) "Viscoplastic tearing of polyethylene thin film", Mechanics of Time-Dependent Materials, 19(2), pp. 187-208. https://doi.org/10.1007/s11043-015-9259-7

Hertzberg, R. W., Vinci, R. P., Hertzberg, J. L. (2012) " Fracture: An Overview", In: Deformation and Fracture Mechanics of Engineering Materials, Wiley, New Jersey, USA, pp. 271-273.
Hu, J., Chen, W., Luo, R., Zhao, B., Sun, R. (2014) "Uniaxial cyclic tensile mechanical properties of ethylene tetrafluoroethylene (ETFE) foils", Construction and Building Materials, 63, pp. 311-319. https://doi.org/10.1016/j.conbuildmat.2014.04.075

Hu, J., Chen W., Zhao, B., Wang, K.. (2015) "Uniaxial tensile mechanical properties and model parameters determination of ethylene tetrafluoroethylene (ETFE) foils", Construction and Building Materials, 75, pp. 200-207.

https://doi.org/10.1016/j.conbuildmat.2014.10.017

Hu, J., Yin, Y., Chen, W., Zhao, B., Yang, D. (2017) "Nonlinear structural behavior of flat-patterning ETFE cushion structures: Experimental observations and numerical simulations", Thin-Walled Structures, 114, pp. 107-115. https://doi.org/10.1016/j.tws.2016.12.027

Kerbow, D. L., (1997) "Ethylene-Tetrafluoroethylene Copolymer Resins" In: Scheirs, J. (ed.) Modern Fluoropolymers: High Performance Polymers for Diverse Applications, Wiley, New Jersey, USA, pp. 311-327.

Knauss, W. G., Emri, I. J. (1981) "Non-linear viscoelasticity based on free volume consideration", Computers and Structures, 13(1-3), pp. $123-128$.

https://doi.org/10.1016/0045-7949(81)90116-4

Kusoglu, A., Santare, M. H., Karlsson, A. M. (2011) "Aspects of fatigue failure mechanisms in polymer fuel cell membranes", Journal of Polymer Science Part B: Polymer Physics, 49(21), pp. 1506-1517. https://doi.org/10.1002/polb.22336

Kwok, K., Pellegrino, S. (2012) "Large Strain Viscoelastic Model for Balloon Film", In: 11th AIAA Aviation Technology, Integration, and Operations (ATIO) Conference, Virginia Beach, USA, pp. 1-17. https://arc.aiaa.org/doi/10.2514/6.2011-6939

LeCuyer, A. (2008) "Material Matters: ETFE", In: ETFE Technology and Design, ETFE. Birkhäuser, Berlin, Germany, pp. 32-41. https://doi.org/10.1007/978-3-7643-8624-5

Lee, E. H., Liu, D. T. (1967) "Finite-Strain Elastic-Plastic Theory with Application to Plane-Wave Analysis", Journal of Applied Physics, 38(1), pp. 19-27. https://doi.org/10.1063/1.1708953

Lee, S. J., Shon, S. D. (2013) "Tensile Strength Characteristics on ETFE Film for Membrane Roof System", Applied Mechanics and Materials, 365-366, pp. 1106-1109.

https://doi.org/10.4028/www.scientific.net/AMM.365-366.1106

Li, J., Kwok, K., Pellegrino, S. (2016) "Thermoviscoelastic models for polyethylene thin films", Mechanics of Time-Dependent Materials, 20, pp. 13-43.

https://doi.org/10.1007/s11043-015-9282-8

Li, Y., Wu, M. (2015) "Uniaxial creep property and viscoelastic-plastic modelling of ethylene tetrafluoroethylene (ETFE) foil", Mechanics of Time-Dependent Materials, 19(1), pp. 21-34. https://doi.org/10.1007/s11043-014-9248-2

Liu, H. (2007) "Material Modelling for Structural Analysis of Polyethylene", Master theses of Applied Science in Civil engineering, University of Waterloo. [online] Available at: http://hdl.handle.net/10012/2646 [Accessed: 23 March 2021] 
Lucas, J., Krombholz, A., Petersilge, M., Schäuble, R., Heilmann, A., Johlke, S., Storgies, E. (2007) "Material properties and mechanical behaviour of pneumatically stabilized ETFE membrane cushions", VDI Berichte, pp. 269-274. [online] Available at: https:// www.researchgate.net/publication/279894438_Material_properties_and_mechanical_behaviour_of_pneumatically_stabilized ETFE_membrane_cushions [Accessed: 22 March 2021]

Moritz, K. (2009) "Time-Temperature Shift (TTS) of ETFE-foils", presetnted at Structural membranes 2009 The 4th International Conference on Textile Composites and Inflatable Structures, CIMNE, Stuttgart, Germany, October, 5-7, 2009.

Moritz, K., Barthel, R. (2002) "Technology: Transparent Architecture Building with ETFE Membranes", Detail, 42(10), pp. 1616-1620.

Nanzai, Y. (1990) "Transition mechanism from elastic deformation to plastic flow in poly(methyl methacrylate)", Polymer Engineering \& Science, 30(2), pp. 96-107. https://doi.org/10.1002/pen.760300206

Perzyna, P. (1966) "Fundamental Problems in Viscoplasticity", Advances in Applied Mechanics, 9, pp. 243-377. https://doi.org/10.1016/S0065-2156(08)70009-7

Popelar, C. F., Liechti, K. M. (1997) "Multiaxial Nonlinear Viscoelastic Characterization and Modeling of a Structural Adhesive", Journal of Engineering Materials and Technology, 119(3), pp. 205-210. https://doi.org/10.1115/1.2812245

Popelar, C. F., Liechti, K. M. (2003) "A Distortion-Modified Free Volume Theory for Nonlinear Viscoelastic Behavior", Mechanics TimeDependent Materials, 7, pp. 89-141. https://doi.org/10.1023/A:1025625430093

Rand, J. L., Henderson, J. K., Grant, D. A. (1996) "Nonlinear behavior of linear low-density polyethylene", Polymer Engineering and Science, 36(8), pp. 1058-1064. https://doi.org/10.1002/pen.10495

Rice, J. C. (1968) "A path-independent integral and the approximate analysis of strain", Journal of Applied Mechanics, 35(2), pp. 379-386. https://doi.org/10.1115/1.3601206

Rigotti, D., Elhajjar, R., Pegoretti, A. (2019) "Adiabatic effects on the temperature and rate dependency of the fracture toughness of an ethylene-fluoroethylene film", Engineering Fracture Mechanics, 214, pp. 260-269.

https://doi.org/10.1016/j.engfracmech.2019.03.005

Schapery, R. A. (1966) "An engineering theory of nonlinear viscoelasticity with applications", International Journal of Solids and Structures, 2(3), pp. 407-425. https://doi.org/10.1016/0020-7683(66)90030-8

Schapery, R. A. (1969) "On the characterization of nonlinear viscoelastic materials", Polymer Engineering and Science, 9(4), pp. 295-310. https://doi.org/10.1002/pen.760090410

Schapery, R. A. (1997) "Nonlinear Viscoelastic and Viscoplastic Constitutive Equations Based on Thermodynamics", Mechanics Time-Dependent Materials, 1, pp. 209-240.

https://oi.org/10.1023/A:1009767812821
Simo, J. C., Hughes, T. J. R. (1998) "Phenomenological Plasticity Models Based on the Notion of an Intermediate Stress-Free Configuration", In: Computational Inelasticity, New York: Springer-Verlag (Interdisciplinary Applied Mathematics), New York, USA, pp 300-335. https://doi.org/10.1007/b98904

Simo, J. C., Taylor, R. L. (1986) "A return mapping algorithm for plane stress elastoplasticity", International Journal of Numerical Methods in Engineering, 22(3), pp. 649-670. https://doi.org/10.1002/nme.1620220310

de Souza Neto, E. A., Perić, D., Owen, D. R. J. (2008) "Finite elements in small-strain plasticity problems", In: Computational Methods for Plasticity: Theory and Applications. Wiley, New Jersey, USA, pp. 191-263.

https://doi.org/10.1002/9780470694626

Tanigami, T., Yamaura, K., Matsuzawa, S., Ishikawa, M., Mizoguchi, K., Miyasaka, K. (1986) "Structural studies on ethylene-tetrafluoroethylene copolymer 1. Crystal structure", Polymer, 27(7), pp. 999-1006. https://doi.org/10.1016/0032-3861(86)90063-7

Uehara, H., Ono, Y., Kakiage, M., Sakamura, T., Masunaga, H., Yukawa, Y., Higuchi, Y., Kamiya, H., Yamanobe, T. (2015) "Property Development for Biaxial Drawing of Ethylene-Tetrafluoroehtylene Copolymer Films and Resultant Fractural Behavior Analyzed by in Situ X-ray Measurements", The Journal of Physical Chemistry B, 119(11), pp. 4284-4293. https://doi.org/10.1021/jp509093g

Williams, M. L., Landel, R. F., Ferry, J. D. (1955) "The Temperature Dependence of Relaxation Mechanisms in Amorphous Polymers and Other Glass-forming Liquids", Journal of the American Chemical Society, 77(14), pp. 3701-3707. https://doi.org/10.1021/ja01619a008

Zhang, C., Moore, I. D. (1997) "Nonlinear mechanical response of high density polyethylene. Part II: Uniaxial constitutive modeling", Polymer Engineering and Science, 37(2), pp. 414-420. https://doi.org/10.1002/pen.11684

Zhao, B., Dong, L., Chen, W., Hu, J., Qiu, Z., Zhou, J. (2017) "Mechanical properties and structural performance of ETFE (ethylene-tetrafluoroethylene) cushion structures at low temperatures", Engineering Structures, 136, pp. 420-429.

https://doi.org/10.1016/j.engstruct.2017.01.031

Zhao, B., Chen, W. (2020) "Experimental study and constitutive modeling on viscoelastic-plastic mechanical properties of ETFE foils subjected to uniaxial monotonic tension at various strain rates", Construction and Building Materials, 263, Article number: 120060 .

https://doi.org/10.1016/j.conbuildmat.2020.120060

Zhao, B., Chen, W. (2021) "Rate-dependent mechanical properties and elastic modulus of ETFE foils used in inflated forming of transparency air-inflated cushion membrane structures", Engineering Structures, 227, Article number: 111404. https://doi.org/10.1016/j.engstruct.2020.111404 